\title{
Oscillation of noncanonical second-order advanced differential equations via canonical transform
}

\author{
MARTIN BOHNER*, KUMAR S. VIDHYAA, AND ETHIRAJU THANDAPANI
}

ABSTRACT. In this paper, we develop a new technique to deduce oscillation of a second-order noncanonical advanced differential equation by using established criteria for second-order canonical advanced differential equations. We illustrate our results by presenting two examples.

Keywords: Advanced differential equation, canonical transform, second-order, oscillation.

2020 Mathematics Subject Classification: 34C10, 34K11.

\section{INTRODUCTION}

Consider the second-order noncanonical advanced differential equation

$$
\left(\mu_{1} \eta^{\prime}\right)^{\prime}(t)+f_{1}(t) \eta(\sigma(t))=0, \quad t \geq t_{0}
$$

subject to

$\left(\mathrm{P}_{1}\right) \mu_{1}, f_{1} \in \mathrm{C}\left(\left[t_{0}, \infty\right),(0, \infty)\right)$,

$\left(\mathrm{P}_{2}\right) \sigma \in \mathrm{C}^{1}\left(\left[t_{0}, \infty\right), \mathbb{R}\right), \sigma^{\prime}(t)>0, \sigma(t) \geq t$ for all $t \geq t_{0}$,

$\left(\mathrm{P}_{3}\right)$ Equation (1.1) is in noncanonical form, that is,

$$
\Omega\left(t_{0}\right):=\int_{t_{0}}^{\infty} \frac{\mathrm{d} t}{\mu_{1}(t)}<\infty .
$$

If $\left(\mathrm{P}_{3}\right)$ does not hold, then we say that (1.1) is in canonical form.

In recent years, there are many results dealing with the oscillation of (1.1) and its modifications for the delay case, that is, $\sigma(t) \leq t$, see for example $[2,4,7,11,12,14]$, and few results in the case of $\sigma(t) \geq t$, see $[1,3,5,6,8-10,13-17,19,20,23]$. Many authors paid attention to a comparison technique, which is a powerful tool in the theory of oscillation, see, for instance, the papers [11, 19, 21, 24] for more details. Further, many authors used the Riccati transformation method to obtain oscillation criteria for delay equations. For the mixed case, that is, $\sigma(t) \leq t$ and $\sigma(t) \geq t$, the author in [22] discussed the oscillatory and nonoscillatory behavior of systems of differential equations based on the analysis of the corresponding characteristic equations. On the other hand in [10], Jozef Džurina already obtained oscillation criteria for the canonical second-order advanced differential equation

$$
\left(r u^{\prime}\right)^{\prime}(t)+p(t) u(\sigma(t))=0
$$

Received: 09.01.2022; Accepted: 13.02.2022; Published Online: 16.02 .2022

*Corresponding author: Martin Bohner; bohner@mst.edu

DOI: $10.33205 / \mathrm{cma} .1055356$ 
from those of a related ordinary differential equation

$$
\left(r u^{\prime}\right)^{\prime}(t)+q(t) u(t)=0 .
$$

In this paper, we will rewrite (1.1) in noncanonical form equivalently as an equation in canonical form, then apply the results established by Jozef Džurina in [10] to the obtained equation in canonical form, thus establishing new results for our equation (1.1) in noncanonical form.

Section 2 contains some preliminary results, the main results are presented in Section 3, and two illustrative examples are offered in Section 4.

\section{Preliminary Results}

Throughout, without loss of generality, considering nonoscillatory solutions of (1.1), we restrict our attention to the positive case, since the negative case is similar.

Lemma 2.1. We have

$$
\left(\mu_{1} \eta^{\prime}\right)^{\prime}=\frac{1}{\Omega}\left(\mu_{1} \Omega^{2}\left(\frac{\eta}{\Omega}\right)^{\prime}\right)^{\prime} .
$$

Proof. A straightforward calculation shows that

$$
\begin{aligned}
\frac{1}{\Omega}\left(\mu_{1} \Omega^{2}\left(\frac{\eta}{\Omega}\right)^{\prime}\right)^{\prime} & =\frac{1}{\Omega}\left(\mu_{1} \Omega^{2} \frac{\eta^{\prime} \Omega-\eta \Omega^{\prime}}{\Omega^{2}}\right)^{\prime} \\
& =\frac{1}{\Omega}\left(\mu_{1}\left(\eta^{\prime} \Omega-\eta\left(-\frac{1}{\mu_{1}}\right)\right)\right)^{\prime} \\
& =\frac{1}{\Omega}\left(\mu_{1} \eta^{\prime} \Omega+\eta\right)^{\prime} \\
& =\frac{1}{\Omega}\left(\Omega\left(\mu_{1} \eta^{\prime}\right)^{\prime}+\mu_{1} \eta^{\prime} \Omega^{\prime}+\eta^{\prime}\right) \\
& =\left(\mu_{1} \eta^{\prime}\right)^{\prime}+\frac{1}{\Omega}\left(\mu_{1} \eta^{\prime}\left(-\frac{1}{\mu_{1}}\right)+\eta^{\prime}\right) \\
& =\left(\mu_{1} \eta^{\prime}\right)^{\prime},
\end{aligned}
$$

completing the proof.

Lemma 2.2. Equation (1.1) can be written in the equivalent canonical form as

$$
\left(\mu z^{\prime}\right)^{\prime}(t)+f(t) z(\sigma(t))=0
$$

where

$$
\mu=\mu_{1} \Omega^{2}, \quad z=\frac{\eta}{\Omega}, \quad \text { and } \quad f=\Omega(\Omega \circ \sigma) f_{1} .
$$

Proof. The equivalence of (1.1) and (2.2) follows from Lemma 2.1. Moreover, since

$$
\int_{t_{0}}^{\infty} \frac{\mathrm{d} t}{\mu_{1}(t) \Omega^{2}(t)}=\lim _{t \rightarrow \infty} \frac{1}{\Omega(t)}-\frac{1}{\Omega\left(t_{0}\right)}=\infty,
$$

(2.2) is in canonical form.

Corollary 2.1. The noncanonical differential equation (1.1) has an eventually positive solution if and only if the canonical equation (2.2) has an eventually positive solution. 
From Corollary 2.1, it is clear that the investigation of oscillation of (1.1) is reduced to that of (2.2), and therefore, we deal with only one class of an eventually positive solution, namely,

$$
z(t)>0, \quad \mu(t) z^{\prime}(t)>0 \quad \text { and } \quad\left(\mu(t) z^{\prime}(t)\right)^{\prime}<0
$$

for $t \geq t_{1} \geq t_{0}$, see [10, Lemma 2.1]. Define

$$
w(t)=\int_{t_{0}}^{t} \frac{\mathrm{d} s}{\mu(s)} .
$$

Now, we state a basic oscillation result given in $[10,18]$, which will be improved in the next section.

Theorem 2.1. Assume that there exists a constant $\delta$ such that

$$
w(t) \int_{t}^{\infty} f(s) \mathrm{d} s \geq \delta>\frac{1}{4}
$$

eventually. Then (2.2) is oscillatory.

\section{Oscillation Results}

In this section, we obtain results for (1.1) by applying results from [10] to the equivalent equation (2.2). If the condition (2.4) fails to hold $(\delta \leq 1 / 4)$, then we can derive a new oscillation criterion using the constant $\delta$.

Theorem 3.2. Let $\eta$ be a positive solution of (1.1) and suppose

$$
w(t) \int_{t}^{\infty} f(s) d s \geq \delta>0
$$

eventually. Then

is increasing eventually.

$$
\frac{\eta(t)}{\Omega(t) w^{\delta}(t)}
$$

Proof. Let $\eta>0$ be a solution of (1.1). By Lemma 2.2, $z>0$ is a solution of (2.2) satisfying (2.3). Hence, the assumption [10, (3.1) of Theorem 3.1] is satisfied, and therefore the conclusion of [10, Theorem 3.1] holds, which says that $z / w^{\delta}$ is strictly increasing, completing the proof.

Next, we present a new comparison result.

Theorem 3.3. Let (3.1) hold. If the differential equation

$$
\left(\mu z^{\prime}\right)^{\prime}(t)+\left(\frac{w(\sigma(t))}{w(t)}\right)^{\delta} f(t) z(t)=0
$$

is oscillatory, then so is (1.1).

Proof. Since [10, assumption $\left(\mathrm{E}_{2}\right)$ of Theorem 3.3] is satisfied, (2.2) is oscillatory, and then so is (1.1).

Using any criterion for the oscillation of (3.2), we immediately obtain an oscillation result for (1.1).

Theorem 3.4. Let (3.1) hold. If there exists a constant $\delta_{1}$ such that

$$
w(t) \int_{t}^{\infty}\left(\frac{w(\sigma(s))}{w(s)}\right)^{\delta} f(s) \mathrm{d} s \geq \delta_{1}>\frac{1}{4}
$$

eventually, then (1.1) is oscillatory. 
Proof. Use [10, Theorem 3.4] to complete the proof.

If the condition (3.3) fails to hold $\left(\delta_{1} \leq 1 / 4\right)$, then we can derive a new oscillation criterion using the constant $\delta_{1}$.

Theorem 3.5. Let (3.1) hold. Assume that $\eta$ is a positive solution of (1.1) and

$$
w(t) \int_{t}^{\infty}\left(\frac{w(\sigma(s))}{w(s)}\right)^{\delta} f(s) \mathrm{d} s \geq \delta_{1}>0
$$

eventually. Then

$$
\frac{\eta(t)}{\Omega(t) w^{\delta_{1}}(t)}
$$

is increasing eventually.

Proof. Use [10, Theorem 3.8] to complete the proof.

Theorem 3.6. Let (3.1) and (3.3) hold. If the differential equation

$$
\left(\mu z^{\prime}\right)^{\prime}(t)+\left(\frac{w(\sigma(t))}{w(t)}\right)^{\delta_{1}} f(t) z(t)=0
$$

is oscillatory, then so is (1.1).

Theorem 3.7. Let (3.1) and (3.3) hold. If there exists a constant $\delta_{2}$ such that

$$
w(t) \int_{t}^{\infty}\left(\frac{w(\sigma(s))}{w(s)}\right)^{\delta_{1}} f(s) \mathrm{d} s \geq \delta_{2}>\frac{1}{4}
$$

eventually, then (1.1) is oscillatory.

The proofs of Theorems 3.6 and 3.7 follow from [10, Theorems 3.9 and 3.10].

For convenience, let us use the additional condition that there is a positive constant $\beta$ such that

$$
\frac{w(\sigma(t))}{w(t)} \geq \beta>1
$$

eventually. Thus, in view of (3.1), conditions (3.3) and (3.5) can be written in simpler forms as

$$
\begin{aligned}
& \delta_{1}=\beta^{\delta} \delta>\frac{1}{4}, \\
& \delta_{2}=\beta^{\delta_{1}} \delta>\frac{1}{4},
\end{aligned}
$$

respectively. Repeating the above process, we have the increasing sequence $\left\{\delta_{n}\right\}$ defined by

$$
\begin{gathered}
\delta_{0}=\delta, \\
\delta_{n+1}=\beta^{\delta_{n}} \delta .
\end{gathered}
$$

Now as in [10, Theorem 3.12], one can generalize the oscillation criteria obtained in Theorems 3.4 and 3.7 .

Theorem 3.8. Let (3.1) and (3.6) hold. If there exists $n \in \mathbb{N}$ such that $\delta_{j} \leq 1 / 4$ for $j=0,1,2, \ldots, n-1$ and

then (1.1) is oscillatory.

$$
\delta_{n}>\frac{1}{4}
$$




\section{EXAMPLES}

We support the obtained results with some examples.

Example 4.1. Consider the second-order advanced differential equation

$$
\left(t^{2} \eta^{\prime}(t)\right)^{\prime}+a \lambda \eta(\lambda t)=0, \quad t \geq 1
$$

where $a>0$. Here $\mu_{1}(t)=t^{2}, f_{1}(t)=a \lambda, \sigma(t)=\lambda t, \lambda>1$. A simple calculation shows that

$$
\Omega(t)=\frac{1}{t}, \quad \mu(t)=1, \quad w(t)=t, \quad f(t)=\frac{a}{t^{2}} .
$$

The transformed canonical equation is

$$
z^{\prime \prime}(t)+\frac{a}{t^{2}} z(\lambda t)=0
$$

Condition (3.1) clearly holds, and (3.3) becomes

$$
a \lambda^{\delta}>\frac{1}{4}
$$

Now $\delta=a$, and by Theorem 3.4, (4.1) is oscillatory provided

$$
a \lambda^{a}>\frac{1}{4}
$$

For example, if $a=\frac{1}{5}$, then we see that $\lambda \geq 3.052$, and for $\lambda=1.8$, we need $a \geq 0.22$.

Example 4.2. Consider the second-order advanced differential equation

$$
\left(t^{2} \eta^{\prime}(t)\right)^{\prime}+0.35742 \eta(1.61 t)=0 .
$$

The transformed canonical equation is

$$
z^{\prime \prime}(t)+\frac{0.222}{t^{2}} z(1.61 t)=0 .
$$

For (4.2), $\delta_{0}=0.222$ and $\lambda=1.61$. A simple calculation shows that

$$
\delta_{1}=0.2468 \text { and } \delta_{2}=0.24968
$$

Therefore, Theorems 3.4 and 3.7 fail for (4.2). But

$$
\delta_{3}=0.25003>\frac{1}{4}
$$

and Theorem 3.8 implies the oscillation of (4.2). However, it is easy to see that [5, Theorems 3, 5, 6], [8, Theorems 3.3, 3.4, and Corollary 4.4] and [4, Theorem 2] do not get oscillation of (4.2). Thus, our result improve these results.

\section{CONCLUSION}

In this paper, we derive oscillation criteria for the noncanonical equation (1.1) by transforming it to the canonical equation (2.2), and then we use the comparison technique available for the canonical equation (2.2) to get new oscillation criteria for the studied equation (1.1). Our oscillation criteria improve [5, Theorems 3, 5, 6], [8, Theorems 3.3, 3.4 and Corollary 4.4] and [4, Theorem 2] for the special case $\alpha=\beta=1$. Finally, the results obtained in [10] cannot be applied to (4.1) and (4.2) since they are of noncanonical type. 


\section{ACKNOWLEDGEMENTS}

The authors would like to thank both anonymous referees as well as the handling Editor Professor Tuncer Acar, for pointing out several shortcomings in the submitted version, which have been fixed in the final version of this paper.

\section{REFERENCES}

[1] R. P. Agarwal, M. Bohner and W. T. Li: Nonoscillation and oscillation: theory for functional differential equations, volume 267 of Monographs and Textbooks in Pure and Applied Mathematics, Marcel Dekker, Inc., New York, 2004.

[2] R. P. Agarwal, S. R. Grace and D. O'Regan: Oscillation theory for second order linear, halflinear, superlinear and sublinear dynamic equations, Kluwer Academic Publishers, Dordrecht, 2002.

[3] R. P. Agarwal, C. Zhang and T. Li: New Kamenev-type oscillation criteria for second-order nonlinear advanced dynamic equations, Appl. Math. Comput., 225 (2013), 822-828.

[4] B. Baculíková: Oscillation of second-order nonlinear noncanonical differential equations with deviating argument, Appl. Math. Lett., 91 (2019), 68-75.

[5] G. E. Chatzarakis, J. Džurina and I. Jadlovská: New oscillation criteria for second-order halflinear advanced differential equations, Appl. Math. Comput., 347 (2019), 404-416.

[6] G. E. Chatzarakis, S. R. Grace and I. Jadlovská: A sharp oscillation criterion for second-order half-linear advanced differential equations, Acta Math. Hungar., 163 (2) (2021), 552-562.

[7] G. E. Chatzarakis, I. Jadlovská: Improved oscillation results for second-order half-linear delay differential equations, Hacet. J. Math. Stat., 48 (1) (2019) 170-179.

[8] G. Chatzarakis, O. Moaaz, T. Li and B. Qaraad: Some oscillation theorems for nonlinear secondorder differential equations with an advanced argument, Adv. Difference Equ., Paper No. 160 (2020), 17 pages.

[9] J. Džurina: Oscillation of second order differential equations with advanced argument, Math. Slovaca, 45 (3) (1995), 263-268.

[10] J. Džurina: Oscillation of second order advanced differential equations, Electron. J. Qual. Theory Differ. Equ., Paper No. 20 (2018), 9 pages.

[11] J. Džurina, S. R. Grace, I. Jadlovská and T. Li: Oscillation criteria for second-order EmdenFowler delay differential equations with a sublinear neutral term, Math. Nachr., 293 (5) (2020), 910-922.

[12] J. Džurina, I. Jadlovská: A sharp oscillation result for second-order half-linear noncanonical delay differential equations Electron. J. Qual. Theory Differ. Equ., Paper No. 46 (2020), 14 pages.

[13] J. Džurina, I. P. Stavroulakis: Oscillation criteria for second-order delay differential equations, Appl. Math. Comput., 140 (2-3) (2003), 445-453.

[14] J. R. Graef: Oscillation of higher order functional differential equations with an advanced argument, Appl. Math. Lett., 111 (2021), Paper No. 106685, 6.

[15] I. Győri, G. Ladas: Oscillation theory of delay differential equations. Oxford Mathematical Monographs. The Clarendon Press, Oxford University Press, New York, 1991. With applications, Oxford Science Publications.

[16] I. Jadlovská: Oscillation criteria of Kneser-type for second-order half-linear advanced differential equations. Appl. Math. Lett., 106 (2020), 106354, 8.

[17] N. Kılıç, Ö. Öcalan, and U. M. Özkan: Oscillation tests for nonlinear differential equations with several nonmonotone advanced arguments, Appl. Math. E-Notes, 21 (2021), 253-262.

[18] T. Kusano, M. Naito: Comparison theorems for functional-differential equations with deviating arguments. J. Math. Soc. Japan, 33 (3) (1981), 509-532. 
[19] T. Li, Y. V. Rogovchenko: Oscillation of second-order neutral differential equations, Math. Nachr., 288 (10) (2015), 1150-1162.

[20] T. Li, Y. V. Rogovchenko: Oscillation criteria for second-order superlinear Emden-Fowler neutral differential equations, Monatsh. Math., 184 (3) (2017), 489-500.

[21] T. Li, Y. V. Rogovchenko: On the asymptotic behavior of solutions to a class of third-order nonlinear neutral differential equations, Appl. Math. Lett., 105 (2020), 106293, 7.

[22] A. M. Pedro: Oscillatory behavior of linear mixed-type systems, Rend. Circ. Mat. Palermo (2), 2021. doi: $10.1007 / \mathrm{s} 12215-021-00658-y$

[23] S. Tang, T. Li, R. P. Agarwal and Martin Bohner: Oscillation of odd-order half-linear advanced differential equations, Commun. Appl. Anal., 16 (3) (2012), 349-357.

[24] C. Vetro, D. Wardowski: Asymptotics for third-order nonlinear differential equations: Nonoscillatory and oscillatory cases, Asymptot. Anal., (2021), 1-19. doi:10.3233/ ASY-211710

\author{
MARTIN BOHNER \\ MISSOURI S\&T \\ DEPARTMENT OF MATHEMATICS AND STATISTICS \\ ROLLA, MO 65409, USA \\ ORCID: 0000-0001-8310-0266 \\ E-mail address: bohneremst . edu \\ KUMAR S. VIDHYAA \\ SRM EASWARI ENGINEERING COLLEGE \\ DEPARTMENT OF MATHEMATICS \\ CHENNAI - 600089 , INDIA \\ ORCID: 0000-0003-2965-4553 \\ E-mail address: vidyacertain@gmail.com \\ ETHIRAJU THANDAPANI \\ UNIVERSITY OF MADRAS \\ RAMANUJAN INSTITUTE FOR ADVANCED STUDY IN MATHEMATICS \\ CHENNAI - 600 005, INDIA \\ ORCID: 0000-0001-6801-4191 \\ E-mail address: ethandapani@yahoo.co.in
}

